\title{
Planning of technical flood retention measures in large river basins under consideration of imprecise probabilities of multivariate hydrological loads
}

\author{
D. Nijssen, A. Schumann, M. Pahlow, and B. Klein \\ Ruhr-University Bochum, Institute of Hydrology, Water Resources Management and Environmental Engineering, \\ Bochum, Germany
}

Received: 27 February 2009 - Revised: 2 July 2009 - Accepted: 27 July 2009 - Published: 6 August 2009

\begin{abstract}
As a result of the severe floods in Europe at the turn of the millennium, the ongoing shift from safety oriented flood control towards flood risk management was accelerated. With regard to technical flood control measures it became evident that the effectiveness of flood control measures depends on many different factors, which cannot be considered with single events used as design floods for planning. The multivariate characteristics of the hydrological loads have to be considered to evaluate complex flood control measures. The effectiveness of spatially distributed flood control systems differs for varying flood events. Event-based characteristics such as the spatial distribution of precipitation, the shape and volume of the resulting flood waves or the interactions of flood waves with the technical elements, e.g. reservoirs and flood polders, result in varying efficiency of these systems. Considering these aspects a flood control system should be evaluated with a broad range of hydrological loads to get a realistic assessment of its performance under different conditions. The consideration of this variety in flood control planning design was one particular aim of this study. Hydrological loads were described by multiple criteria. A statistical characterization of these criteria is difficult, since the data base is often not sufficient to analyze the variety of possible events. Hydrological simulations were used to solve this problem. Here a deterministic-stochastic flood generator was developed and applied to produce a large quantity of flood events which can be used as scenarios of possible hydrological loads. However, these simulations imply many uncertainties. The results will be biased by the basic assumptions of the modeling tools. In flood control planning probabilities are applied to characterize uncertain-
\end{abstract}

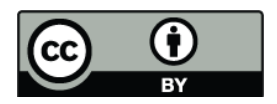

Correspondence to: D. Nijssen (david.nijssen@rub.de) ties. The probabilities of the simulated flood scenarios differ from probabilities which would be derived from long time series. With regard to these known unknowns the bias of the simulations was considered by imprecise probabilities. Probabilities, derived from measured flood data were combined with probabilities which were estimated from long simulated series. To consider imprecise probabilities, fuzzy sets were used to distinguish the results between more or less possible design floods. The need for such a differentiated view on the performance of flood protection systems is demonstrated by a case study.

\section{Introduction}

Flooding is the major cause of damage of all natural catastrophes in Germany (Thieken et al., 2007). Following the severe floods that affected Europe at the turn of the millennium, the risk perception increased significantly, giving rise to a higher demand for risk management. The risk management process consists of three main components: risk estimation, risk evaluation and risk control/communication (Fell and Hartford, 1997). With the need to characterize risk, a shift has taken place from safety-oriented flood defence towards integrated flood risk management (Plate, 2002). Under consideration of the impossibility of an absolute protection against flooding by technical measures, decision makers are forced to accept that remaining risks have to be considered. Integrated flood risk management has to combine flood risk analysis with measures which are appropriated for risk reduction, a planning approach which differs significantly from safetyoriented flood planning in the past. In the safety-oriented planning a certain flood event is defined and used as a design

Published by Copernicus Publications on behalf of the European Geosciences Union. 
flood. The two basic assumptions of this flood design concept are:

- The design flood defines the limit up to which a flood can be controlled completely by technical measures.

- A failure of the system has to be expected only in such cases where the design flood is exceeded.

Under these assumptions, design floods with very small probabilities are often used. Thus the risk of occurrence of a flood beyond the design flood seems to be very small. In many cases this remaining risk has even been neglected. The remaining risk of failure, which may result from the hydrological risk of an extreme flood, but also from other sources as operational and technical risks, has to be considered in a risk-based planning approach (Plate and Meon, 1988). An assessment of the effectiveness of flood protection measures is needed to specify the remaining risk.

What does this shift in paradigm mean for hydrology? The efficiency of flood control and the reliability of water resources systems depend to a large extent on hydrological information used for planning. Flood risk results from the combination of the natural hazard, the potential losses and the vulnerability of the affected exposure unit (Merz, 2006). Hydrology describes the hydrological risk by characterizing the flood event with its probability. The question arises which of the multiple characteristics of a flood is defined with this probability: peak, volume, shape or (in large river basins) the coincidence of floods in the different tributaries? Mostly the flood peak is characterized by its probability and all other characteristics are fixed and related to this peak. This can be accepted in safety oriented planning (if the safety of a structure has to be demonstrated), but this specification of a critical hydrological load is inappropriate for risk-based planning. If the remaining risks have to be specified, events, where a partial or total failure of the flood protection system can be expected, have to be considered. It is insufficient to show how the system would function if a defined design flood were to occur. A large amount of possible hydrological loads should be considered to demonstrate under which conditions the performance of the planned flood control system would be low and to demonstrate the impacts of possible failures. Based on these analyses the efforts for risk reduction can be compared with the remaining risks.

Hydrological time series are often too short, nonhomogenous or non-stationary to provide the information about the large range of hydrological loads which is needed in such analyses. However, there is an option to generate a data base with stochastic means. Most of those attempts are based on complex simulations, starting with stochastic generation of precipitation and transforming the results with a deterministic hydrological model into a runoff time series (e.g. Blazkova and Beven, 2002; McMillan and Brasington, 2008). It can be shown that this methodological approach implies many uncertainties (Lamb and Kay, 2004; Cameron et al., 1999). A probabilistic characterisation of the results is difficult, as several stochastic assumptions are incorporated. For example the meteorological load has a probability as well as the initial state of the deterministic hydrological model, the model parameters itself are uncertain, the behaviour of the model for extreme events, which are often higher than any observed flood, is uncertain, the impact of technical flood retention measures depends on unknown operation schemes and so on. These problems aggravate if such analyses are done for a large river basin with spatially distributed hydrological loads, where many different combinations of influencing factors are possible. Many of the influencing factors can not be characterized by probabilistic means. Nevertheless, simulations are the sole way to specify the complexity of possible hydrological conditions in cases where the data base is insufficient.

In the following a methodology is presented which uses a stochastic rainfall generator coupled with a deterministic hydrological model for the river basin. The developed deterministic model incorporates the effects of existing flood retention structures, thereby considering the complex dependencies between their performance and specific characteristics of flood events. The simulated flood events were analysed with multivariate statistics. The interdependencies between simulated volumes and peaks and interactions of tributaries during the simulated flood events were characterized with multivariate statistical means. Based on these analyses single scenarios were selected and used to assess the performance of planned extensions of the flood retention system. Different stages of enlargements of the flood polders were analysed. Under consideration of the large uncertainties of this methodology, the applied scenarios were characterized by imprecise probabilities. Only one characteristic, the statistical return period of the flood peak at the inflow point into the flood retention system, was defined by probabilities which were based on measured data. Comparing the return period of the peak with joint return periods of the volumepeak combinations and the probabilities that a coincidence of floods of two tributaries occurs, typical and non-typical flood scenarios were differentiated. For a typical scenario the probabilities of peak and volume or peak and flood coincidence of tributaries are similar but for non-typical floods these probabilities differ significantly. As these differentiations are based on simulations, the results are uncertain. This uncertainty is handled with fuzzy logic in the MultiCriteria Decision Making (MCDM) procedure which was applied to compare the different stages of the extension of the flood control system. A MCDM-method was applied since many conflicting criteria have to be considered. The conflicts resulted mainly from the limitations of technical flood control systems to ensure an absolute protection. It became evident that the risk for damages may increase (compared with the actual stage of extension), if new planned elements of the flood retention system would fail. This is especially a problem for flood polders which are situated in natural 
flood plains of rivers. These areas would naturally act as flood retention areas during extreme floods, but are now used for technical flood retention during the rising limb of hydrographs. Often the retention capacity is exhausted before the peak of an extreme flood is reached.

\section{Methodology}

\subsection{Stochastic-deterministic generation of flood scenarios for large river basins}

An analysis of the performance of flood control measures in a large river basin has to consider a large variety of different flood events. As hydrological time series can often not represent this complexity, different scenarios have to be defined, which should cover the wide range of possible circumstances. These scenarios can be derived from simulations. At the design stage of flood control works, simulations of possible discharge series are required. These series are not "real" in the sense of being expected, but they are examples of what could occur (Kachroo, 1992). Such flood events are treated as being typical for the conditions under which the flood control system is operated. A precondition of simulations is a characterisation of the stochastic structure of precipitation. With regard to the large size of the river basin of interest a spatially distributed rainfall generator was developed, which describes the stochastic behaviour of point measurements as well as the spatial correlation of daily rainfall values. A stochastic model for the generation of daily time series of rainfall at multiple locations was used, in which the amount of daily rainfall was modelled by a mixture of two different probability distribution functions (Hundecha et al., 2009).

To simulate a long time series of runoff from the stochastically simulated precipitation sequences a semi-distributed hydrological model, based on an object-oriented framework and following the concept of HBV-96 (Lindström et al., 1997) has been applied. As the runoff conditions within the simulated river basin were affected by several reservoirs which were constructed for flood control, a reservoir module for controlled and uncontrolled flood management was integrated. This module allows for consideration of the specific hydraulic conditions of reservoirs with regard to the bottom outlet and the spillway and can be used to simulate different operation rules. This hydrological model was applied to simulate a long time series of discharge values at several locations within the river basin with daily time steps. To avoid the difficulties of a stochastic simulation of other meteorological variables which were needed for the simulation of the water balance, here an observed time series of 40 years with measured daily data of temperature, radiation and air humidity were used. These series were repeated 250 times (in total 10000 years were simulated). With regard to the large number of random combinations of precipitation values with other meteorological variables, a realistic representation of the hydrological conditions can hence be expected. To demonstrate this, the statistics of precipitation and runoff values estimated at gauges were compared with statistics from the simulated series. The basic assumptions of this methodological approach are:

- The stochastic rainfall generator is able to reproduce the spatial and temporal distribution of precipitation within the river basin,

- The hydrological model represents the runoff generation and the flood wave propagation within the river basin in an appropriate way (this precondition can not be validated for very large events),

- The spatial and temporal distribution of rainfall within the river basin is the most important factor with regard to the flood climatology within the river basin.

The 10000 year time series of daily runoff data was analysed by means of multivariate statistics (see Sect. 2.2) to select 31 events, which were used as flood scenarios. The number of events which could be simulated in detail was limited due to the high CPU requirements of the hydraulic model. The Copula-based statistics provided criteria which were used to select such events appropriately. Thus the spatial structure and the relationships between flood peaks and volumes at the inflow of the two reservoirs were modified to ensure that events, which have not been observed in the past, but which seem to be probable, were included. These selected events were simulated with an hourly time step to ensure that the flood dynamics and the effects of flood control measures are represented in an appropriated way. To do this, the series of daily precipitation have been disaggregated into hourly time values using the tools HYETOS (Koutsoyiannis et al., 2003) and MuDRain (Koutsoyiannis and Onof, 2001). The return period of the peak was chosen as a basic characteristic of all flood events. Six different return periods were considered ( $T=25,50,100,200,500,1000$ years). For each of these classes of return periods five flood events were selected (and one extreme event with $T>1000$ ), which differ in their shape, their volume and the spatial distributions of runoff. The probabilities of these multivariate characteristics were assessed by multivariate statistics.

\subsection{Categorising hydrological loads with multivariate statistics}

Joint probabilities of relevant flood properties can be used to characterise the different hydrological scenarios. This is necessary for risk-based planning, as univariate frequency analysis, which defines the return period of a flood e.g. by its peak, may lead to an over- or underestimation of the risk associated with a given flood (see e.g. Salvadori and De Michele, 2004). Copulas can be used for the construction of bivariate distribution functions. They have been extensively used 
in the areas of financial studies but more recently copulas also have been implemented in hydrology for multivariate analysis of hydrological random variables (see e.g. Favre et al., 2004; Grimaldi and Serinaldi, 2006; Salvadori and De Michele, 2004; Klein et al., 2009). A bivariate distribution for two correlated random variables $X$ and $Y$ with the univariate marginal cumulative density functions $F_{X}(x)$ and $F_{Y}(y)$ can be expressed using copulas. A copula is a function which exactly describes and models the dependence structure between correlated random variables independently of the marginal distributions. The link between the copula function and the joint distribution is provided by the theorem of Sklar (1959):

$$
\begin{aligned}
& F_{X, Y}(x, y)=\operatorname{Prob}(\mathrm{X} \leq \mathrm{x}, \mathrm{Y} \leq \mathrm{y}) \\
& \quad=C\left[F_{X}(x), F_{Y}(y)\right]=C(u, v),
\end{aligned}
$$

where $F_{X, Y}(x, y)$ is the joint cumulative distribution function (CDF) of the random variables and $C$ is the copula function defined as mapping $C:[0,1]^{2} \rightarrow[0,1]$. Because copulas are invariant under strictly increasing transformations of $X$ and $Y$ we concentrate on the two uniformly distributed random variables $U$ and $V$ on $[0,1]$.

A large variety of copulas is available to model multivariate dependencies. Here the two parameter BB1 copula (Joe, 1997):

$$
\begin{aligned}
& C_{\theta}(u, v)=\left\{1+\left[\left(u^{-\theta_{1}}-1\right)^{\theta_{2}}+\left(v^{-\theta_{1}}-1\right)^{\theta_{2}}\right]^{1 / \theta_{2}}\right\}^{-1 / \theta_{1}}, \\
& \theta_{1}>0, \theta_{2} \geq 1
\end{aligned}
$$

was selected for the bivariate analysis.

There are two different exceedance probabilities using bivariate frequency analysis:

The probability with which the random variables $X$ and $Y$ both exceed $x$ and $y$ is defined as

$$
\begin{aligned}
& P(X \geq x \wedge Y \geq y) \\
& =1-F_{X}(x)-F_{Y}(y)+F_{X, Y}(x, y) \\
& =1-F_{X}(x)-F_{Y}(y)+C\left[F_{X}(x), F_{Y}(y)\right]
\end{aligned}
$$

with the corresponding joint return period in which $x$ and $y$ are exceeded being expressed as

$$
\begin{aligned}
T_{X, Y}^{\wedge} & =\frac{1}{P(X \geq x \wedge Y \geq y)} \\
& =\frac{1}{1-F_{X}(x)-F_{Y}(y)+C\left[F_{X}(x), F_{Y}(y)\right]}
\end{aligned}
$$

and the probability of $X$ or $Y$ exceeding the thresholds $x$ or $y$ is defined as

$$
P(X \geq x \vee Y \geq y)=1-F_{X, Y}(x, y)=1-C\left[F_{X}(x), F_{Y}(y)\right],
$$

with the joint return period in which either $x$ or $y$ are exceeded written as

$$
T_{X, Y}^{\vee}=\frac{1}{P(X \geq x \vee Y \geq y)}=\frac{1}{1-C\left[F_{X}(x), F_{Y}(y)\right]} .
$$

More detailed descriptions of the copula methods can be found in Genest and Favre (2007), Joe (1997), Nelsen (1999), Salvadori and De Michele (2004) and Salvadori et al. (2007). By applying copulas the multivariate statistics of the generated floods can be described. Here the interdependencies between peak and volume but also the probabilities of coincidences of flood events in tributaries were considered. Since these statistical descriptions are based on simulated data and only one statistical characteristic, the return period of flood peaks, could be compared directly with measured discharge data, the probabilities derived from copula analyses were not integrated directly in the MCDM process. Here bivariate copula probabilities were used to differentiate between plausible and less plausible events within the classes of equal return periods of the flood peaks. This is done with a measure of plausibility which is described in the following.

\subsection{Characterisation of hydrological loads with imprecise probabilities}

The assumption that flood events with similar peaks but different volumes or caused by different spatial distributions of precipitation and runoff within the basin will have the same probabilities is not correct. The multivariate characteristics and their interdependencies can be characterised with copulas. However - as the data base was derived from complex simulations the probabilities of flood scenarios are uncertain. Nevertheless, the copula-based statistical information provides opportunities to differentiate among the design flood scenarios. Here this information is used as imprecise probabilities. Imprecise probabilities are a way to consider uncertainties of probabilistic assessments. The imprecision in expressing probabilities, which was very much stimulated by Walley (1999), introduced a new dimension into the formalization of uncertainty and uncertainty-based information. Events which belong to one set of floods according to the return period of the peak may differ in other characteristics. These differences were analysed with Copula statistics. The resulting statistical measures are used as additional information to specify the events in a possibilistic way. There are typical events where the return period of the peak and the return periods of other characteristics are similar and less typical events where these probabilities differ significantly. Fuzzy sets are one way to specify uncertainties (Klir and Smith, 2001). According to fuzzy theory the membership of a single event within a set of flood events of a certain return period is specified by a function characterising the grade of membership. A flood is seen as fuzzy event which has a probability measure (return period of the peak) and a degree of membership (Zadeh, 1965). Zadeh (2005) suggested in his generalised theory of uncertainty the application of fuzzy sets for possibilistic modalities of generalised constraints.

A generalised constraint is a constraint of the form:

$X$ is $r R$ 
where $X$ is the constrained variable, $R$ is a constraining relation and $r$ is an indexing variable, which is blank for possibilistic constraints. Therefore,

Poss $\{X=u\}=\mu_{A}(u)$

where $u$ is a generic value of $X, \mu_{A}$ is the membership function of $A$ and $A$ is a set of values in $X$.

The fuzzy number $A=(l, m, u)$ with $l \leq m \leq u$ is a triangular fuzzy number, if the membership function can be written as (Zadeh, 1965):

$\mu_{A}(x)=\left\{\begin{array}{c}0 \text { for } \quad x \leq l \\ \frac{x-l}{m-l} \text { for } l<x \leq m \\ \frac{u-x}{u-m} \text { for } m<x \leq u \\ 0 \text { for } u<x\end{array}\right.$

Triangular fuzzy numbers are one of the simplest forms of fuzzy numbers. Generally, they are described by three real numbers as $\tilde{A}=(l, m, u)$ where $l \leq m \leq u$ represent the lower, modal and upper value of the fuzzy number. The modal value has a membership value of $\mu_{A}(m)=1$. Here the highest value of the membership function $\left(\mu_{A}(u)=1\right)$ was attributed to events where the bivariate copula probabilities are nearly the same as the probability of the flood peak. Such flood events seem to be most representative for a certain return period with regard to the agreement of the different statistical characteristics of the flood. If e.g. the return period which was estimated from the joint probability of peak and volume is greater than the return period of the peak, the event is less probable than expected from the return period of peak alone. If this concordance between return periods is not given, e.g. if the joint volume-peak-probability indicates a more common event, the return period of the flood peak seems to be less plausible.

To consider these differences a characteristic "plausibil-

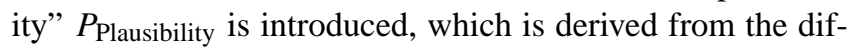
ferences in probabilities:

$P_{\text {Plausibibity }}=\left\{\begin{array}{c}\operatorname{Min}\left(\frac{T_{\text {Peak Volume }}^{\vee}}{T_{\text {Pealk }}^{\vee}} ; \frac{2 \cdot T_{\text {Peak }}-T_{\text {Peak Volume }}^{\vee}}{T_{\text {Peak Volume }}}\right), \forall T_{\text {Peak, Volume }}^{\vee} \in\left[0 ; 2 \cdot T_{\text {Peak }}\right](10) \\ 0, \forall T_{\text {Peak , Volume }}^{\vee} \notin\left[0 ; 2 \cdot T_{\text {Peak }}\right]\end{array}\right.$

$T_{\text {Peak }}$ and $T_{\text {Peak,Volume }}^{\vee}$ are the return periods based on the flood peak statistics or on the copula statistics of flood peak and volume.

The flood scenarios with a certain return period of the peak were analyzed separately after fuzzification of their plausibility. The other characteristics such as the volume and shape of the hydrograph vary within these groups and describe the uncertainty range, which can be specified with triangular fuzzy numbers.

\subsection{Impact assessments of flood control measures}

A hydraulic model was applied to describe the flood wave propagation and the hydraulic effects of flood polders and to specify the inundation areas which are expected for different flood scenarios. Due to the large number of simulations a computationally efficient coupled 1-D-2-D hydraulic model (Kamrath et al., 2006) was used. The 1-D model is based on the St.-Venant-equations, whereas the 2-D model has been implemented using an "initially dry land" approach that embodies storage cells. An implicit integration scheme is used to improve computational efficiency. The coupling of 1-D-1-D/1-D-2-D is bidirectional. Based on land use data and detailed analyses of the social and economic conditions within flood exposed areas, socio-economic flood damages were estimated depending on the height of flooding and flow velocities. The possible impacts of inundations were considered by the number of affected inhabitants and the total damages, which were differentiated between damages in rural areas and settlements. The benefits of the flood control system can be characterized by reduced peak flows and their respective water levels. Thus the differences between the present situation and different flood protection measures were estimated.

\subsection{Integration of fuzzy numbers in Multiple Criteria Decision Making (MCDM)}

Decisions about the degree of flood protection are very complex, as many different interacting criteria have to be considered such as different risks, mitigation strategies and stakeholders (Berlekamp et al., 2005). Even if risks can be quantified, risk reduction is a political task as the decision makers have to decide about safety, costs and remaining risks which possess a normative, qualitative, and political nature into the decision process (Haimes, 1998).

The complexity of the decision problem places severe restrictions on the degrees of detail, which can be offered to decision makers. Scientific information about hydrological risk is only one of many components which contribute to decisions concerning flood protection. If the scientific uncertainties are emphasized too much it complicates the already difficult process of decision making (Morss, 2005). Better and more complete information does not necessarily lead to better policies; very complex information can affect the decision making process negatively. Beven (2006) mentions the risk of undermining the confidence of stakeholders.

However, it remains important that during the decision process, the inherent uncertainties are incorporated. Otherwise the stochastic character of floods and the variability within distributions of benefit and cost leads to a false sense of safety and underestimation of remaining risks. Uncertainty related to the outcome or occurrence of flood events should not prevent a flood control planning. However, improved communication - not only to those who make regulatory decisions on the basis of such information, but also to stakeholders and the general public (Krupnick et al., 2006) is essential. 
In order to provide the information to decision makers in a structured way, the flood risk data should be characterized within a MCDM, which can be integrated in a decision support system (DSS). The MCDM technique should allow for incorporation of both qualitative and quantitative data, it should organise the complexity of the multicriterial decision system in a clear hierarchical structure and should integrate uncertainty in the analysis. Here the results of the risk analysis for flood control planning were presented as fuzzy numbers. The MCDM-algorithm used in this study is the fuzzyanalytical-hierarchy-process (F-AHP) based on the classical AHP formulated by Saaty (1980) (Van Laarhoven and Pedrycz, 1983; Boender et al., 1989; Deng, 1999). The hierarchic structure provides the opportunity to organize criteria and subcriteria in a hierarchic way. The fuzzy approach allows a higher degree of freedom in specifying weights among criteria. The methodology is summarised in Fig. 1.

\section{Case study}

\subsection{Description of the case study basin}

The methodology described above has been applied to the Unstrut river basin in the central part of Germany. The Unstrut watershed has an area of $\sim 6400 \mathrm{~km}^{2}$ and is situated partly in the Federal State of Thuringia and partly in the Federal State of Saxony-Anhalt (Fig. 2). This geographic location results in an uneven distribution of benefits and burdens of flood control. The upstream flood control system belongs to Thuringia, but many of the flood protected areas are situated in Saxony-Anhalt. The catchment has variable topographic structure, with lower regions in the central part, the Harz Mountains in the North and the Thuringian Forest in the South.

At the moment the current technical flood retention system within this river basin consists of the reservoir Kelbra and the reservoir Straussfurt, of several small reservoirs of local importance, a flood channel and a flood polder system with five polders between the cities of Oldisleben and Wangen (see Fig. 2). In total the flood retention system has a volume of $\sim 100$ Mio. $\mathrm{m}^{3}$. The reservoir Kelbra is operated by the state of Saxony-Anhalt, whereas the remaining flood retention facilities are operated by the state of Thuringia. In communication with the local authorities a set of planned flood control measures were developed, varying from the optimization of the existing polders, increase of retention time within polders by additional check dams, creation of new polders, variation of the inlet regulation (controlled and uncontrolled flooding) and alteration of the polder inlet structures. These measures were clustered into six different stages of extension of the flood retention system. The existing stage of extension is denoted as stage 1 and the most complex stage as stage 6 (see Table 1).
Table 1. System stages of the flood control system considered in this study.

\begin{tabular}{|c|c|}
\hline $\begin{array}{l}\text { System } \\
\text { Stage }\end{array}$ & Specifications \\
\hline SS1 & $\begin{array}{l}\text { Current stage. Only a small percentage of system } \\
\text { retention capacity can be used due to malfunctioning } \\
\text { technical elements. Polder system consists of five } \\
\text { polders }\left(\sim 45 \text { million } \mathrm{m}^{3}\right)\end{array}$ \\
\hline $\mathrm{SS} 2$ & $\begin{array}{l}\text { Current stage fully operational. Polder system consists } \\
\text { of five polders polders }\left(\sim 45 \text { million } \mathrm{m}^{3}\right) \text {. } \\
\text { Retention capacity enhanced by check dams }\end{array}$ \\
\hline SS3 & $\begin{array}{l}\text { Extension of the system. Stage } 2 \text { with four additional } \\
\text { polders to increase the retention volume } \\
\text { In total about } \sim 77 \text { million } \mathrm{m}^{3}\end{array}$ \\
\hline SS4 & $\begin{array}{l}\text { Alternative extension of the system. Stage } 2 \text { with } \\
\text { four larger polders than in SS3. In total about } \sim 85 \text { million } \mathrm{m}^{3} \\
\text { Polder inlet structures not controlled }\end{array}$ \\
\hline SS5 & Stage 4 but with controlled polder inlets \\
\hline SS6 & $\begin{array}{l}\text { Extension and operation of the system as in stage } 5 \text { plus } \\
\text { widening of the polder inlet structures }\end{array}$ \\
\hline
\end{tabular}

\subsection{Specification of hydrological loads}

As described under point 2.1 a long series of runoff (10000 years) was simulated on a daily basis. These data were essential for this study as the measured discharge data were affected by the construction of two flood reservoirs and river regulations. Thus the flood regime of the river basin could be characterised only by hydrological modelling. The inflow gauge situated upstream of the flood reservoirs was used to verify the flood statistical results provided by the stochasticdeterministic simulations with the statistics of a series of 40 years measured discharge data. Furthermore, a multivariate statistical analysis of simulated data with regard to the relationship between flood peak and volume has been carried out.

Generally, flood peak and flood volume are two statistically dependent variables. Therefore the joint return period of the values of the annual flood peak and the corresponding volume of the inflows to the dam Straussfurt was used to categorize the hydrological scenarios selected for the design of the flood control system. The copula method was used to express the bivariate distribution function. The first step of the bivariate frequency analysis using copulas was the estimation of the marginal distributions of the two random variables. It was found that each variable could be described in an appropriate way with the Generalized Extreme Value (GEV) distribution. The second step was the selection of a suitable copula to describe the dependencies between the random variables. Diverse copula functions were fitted to the database. The two-parameter copula BB1 (see Eq. 2) reflected best the dependence structure between the random variables. A detailed description of the model selection and the copula analysis is given by Klein et al. (2009). 


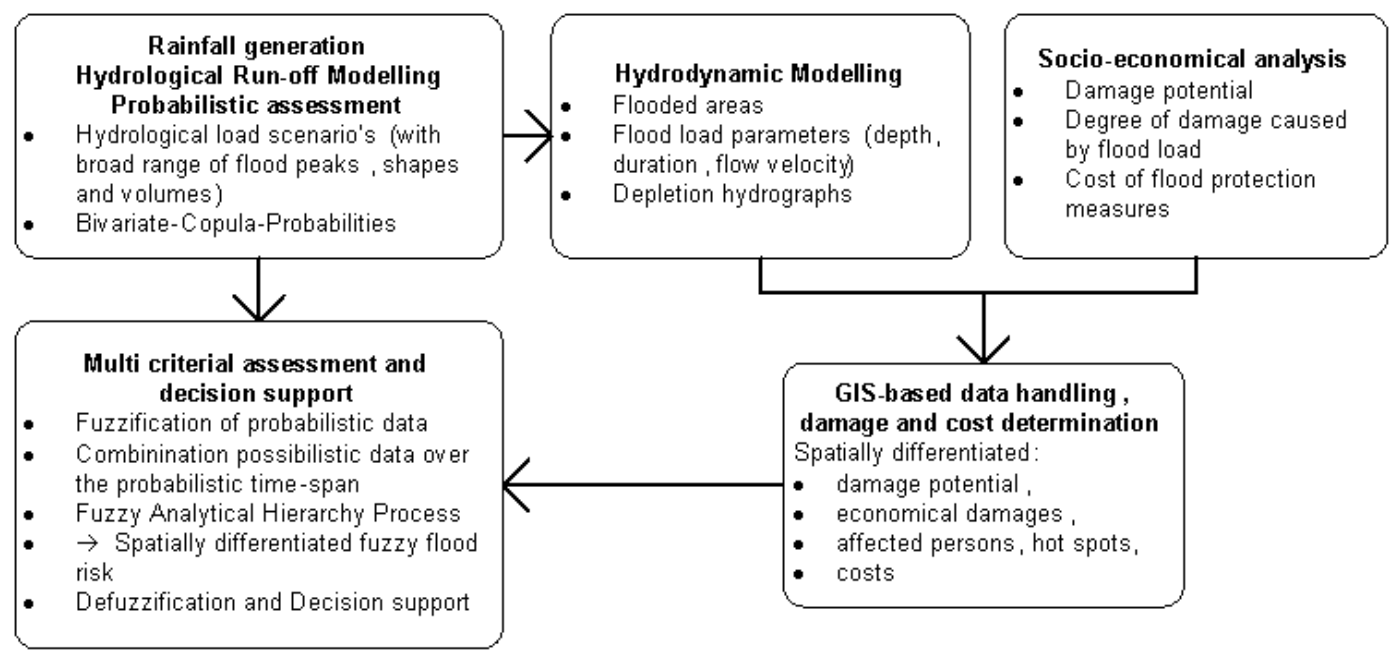

Fig. 1. Flowchart depicting the different steps and model components to integrate hydrological uncertainties in flood control planning.

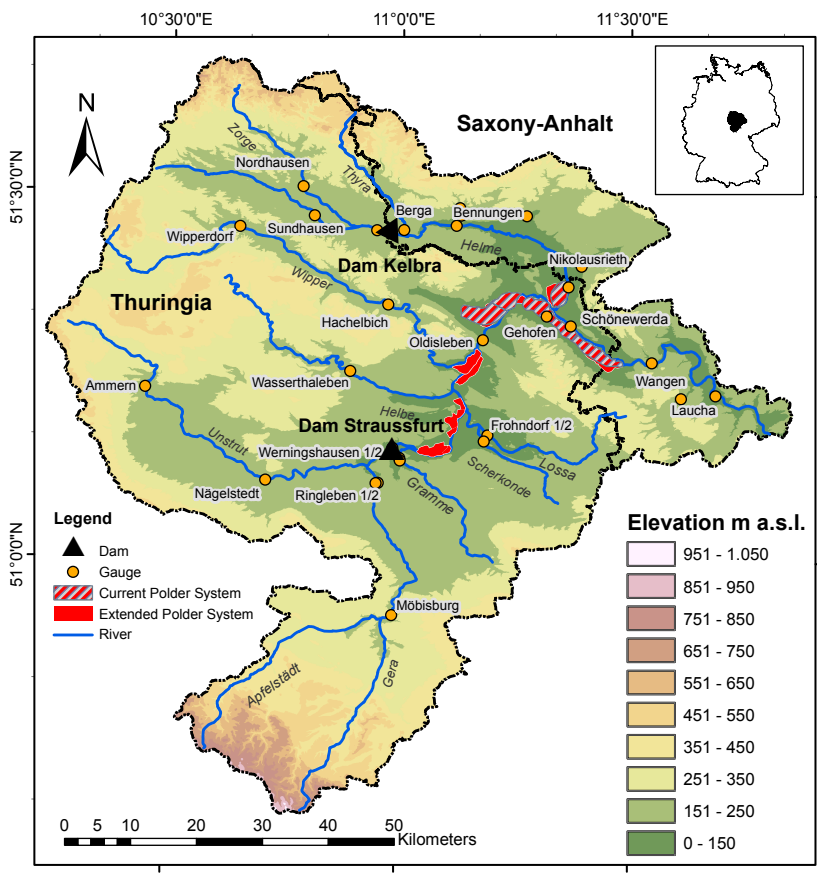

Fig. 2. Topographical map of the Unstrut catchment in Thuringia and Saxony-Anhalt. Also shown are the technical flood retention system (current and extended) and important gauges within the catchment.

Figure 3 illustrates the contours of the joint return periods $T_{X, Y}^{\wedge}$ (for which $X$ and $Y$ ) and $T_{X, Y}^{\vee}$ (for which $X$ or $Y$ exceed their respective tresholds $x$ and $y$ ) with respect to the flood peak $(X)$ and the corresponding volume $(Y)$ and the annual events from the simulated time series. For example events with a flood peak of a 100 year return period the corresponding return periods of the flood volume range between 10 years and 2000 years. This demonstrates that it is recom-

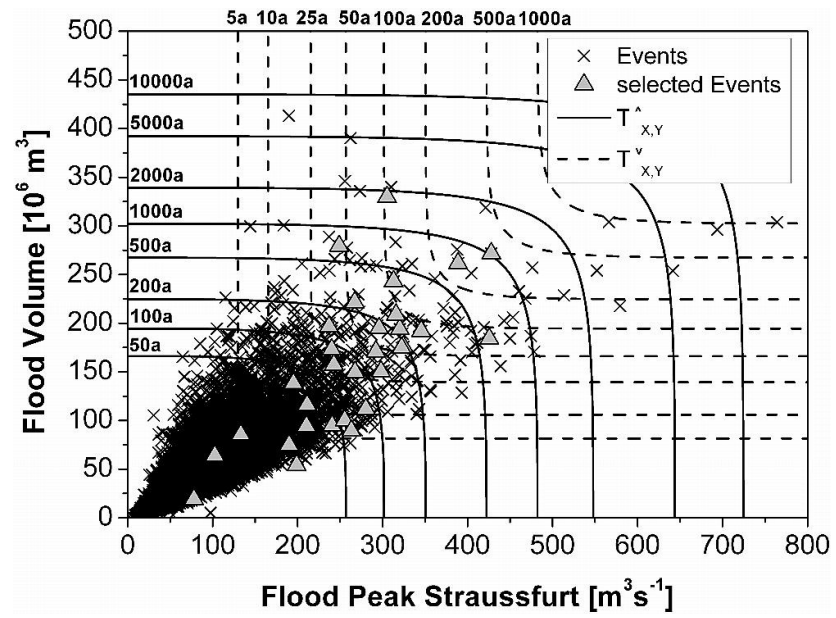

Fig. 3. Joint return periods $T_{X, Y}^{\vee}$ (exceeding $x$ or $y$ ) and the $T_{X, Y}^{\wedge}$ (exceeding $x$ and $y$ ) of the corresponding flood peak and volume.

mendable to use joint probabilities for a detailed description of flood varieties instead of a univariate probability of the flood peak only.

Based on 10000 years simulated runoff 31 flood events were selected. For each return period of 20, 50, 100, 200, 500 and 1000 years five events were selected which were covering a large range of spatial distributions of runoff and peak-volume relationships. Event number 31 was an extreme flood ( $T>1000$ years), which was used to specify the upper limit of possible damages. In Fig. 4 the inflow-outflow relationships of two floods with a return period of the peak of 100 years are shown to demonstrate the necessity for a multivariate approach. In this example both events have a flood peak of about $300 \mathrm{~m}^{3} / \mathrm{s}$. Their peaks classify both of them with a statistical return period of 100 years. However (as it is shown in Fig. 4) both floods have strongly differing hydrographs. 

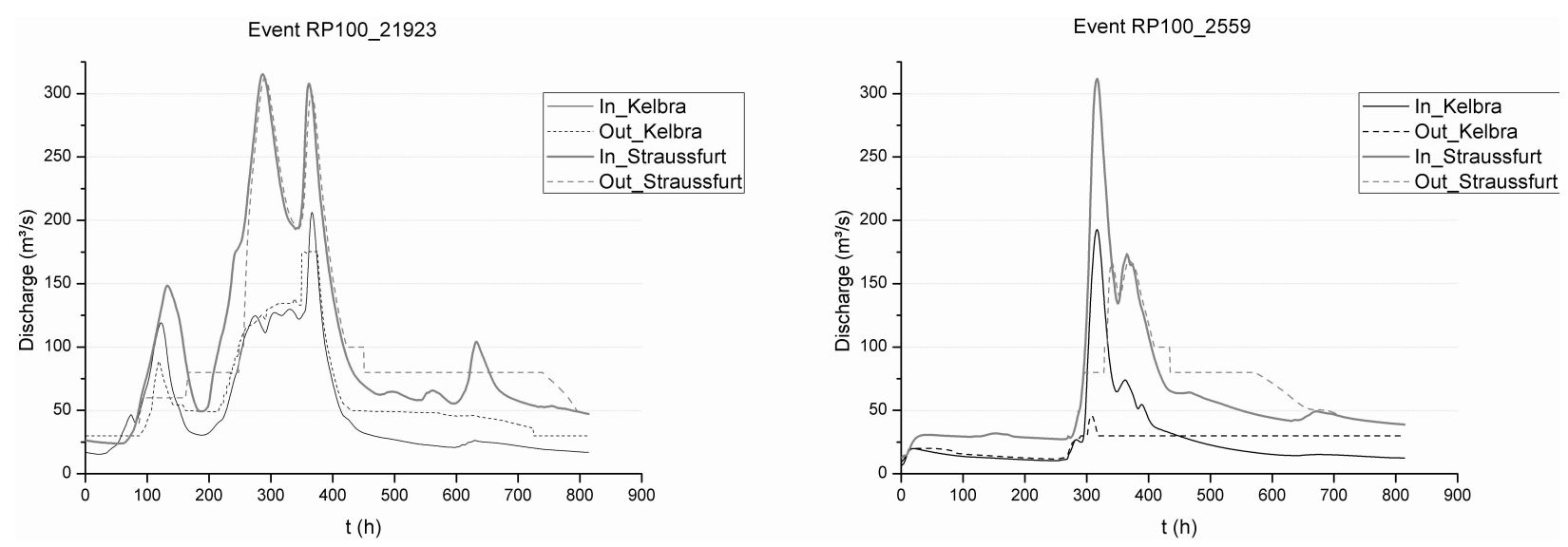

Fig. 4. Inflow (left) and outflow (right) hydrograph of the dam Kelbra (North) and detention basin Straussfurt (South).

The large flood on the left has a preliminary peak, two large peaks and a large volume and can not be buffered by the existing flood reservoir. Compared with the second flood (on the right) it causes damages that are about 30 times higher. The analysis of the bivariate copula probability of flood peak and volume reveals that the flood with the large volume has a multivariate return period of 681 years, whereas the other flood has a bivariate return period of only 134 years. In this case, it would obviously be wrong to attribute the same possibility to both events.

But also the spatial rainfall distribution has large impacts on the effectiveness of the flood control system. The flood volume, triggered by the rainfall event 2320 (see Fig. 5 on the left) is considerably smaller than for the event 2559 (shown on the right in Fig. 5). It can be fully retained by the Straussfurt reservoir as it has only one flood peak, in contrast to the event 2559. Although the peaks are of the same size, the computed damages of the 2320 flood were 6 times higher than the damages of the flood 2559. The main cause for this difference is the spatial distribution of the rainfall: the 2559 rainfall volume is distributed among the watersheds in the Northern part of the basin as well as in the Southern part, where the runoff can be controlled. This is not the case for the event 2320, where the main rainfall volume bypasses both components of the flood retention system. As the relatively small amount of the 2320 rainfall volume which passes the inflow gauge of the reservoir Straussfurt results in a univariate return period of the flood peak of 100 years, this event is a non-typical 100-years flood. Here the return period has to be corrected based on a multivariate probability to become representative for the entire basin. Applying the multivariate copula statistics to analyse the return period of this event for the gauges at Straussfurt and Kelbra jointly it can be shown that the event 2320 is three times more frequent than the event 2559.

For 186 flood events ( 31 hydrological loads and six different stages of extension of the flood control system), the fol-
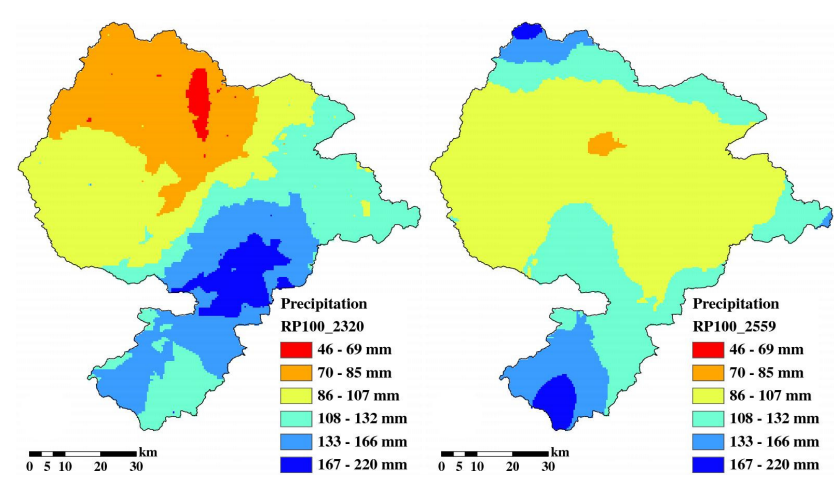

Fig. 5. Precipitation distribution in the basin of the Unstrut for the two events with exceedance probabilities of the flood peaks of 0.01 : event 2320 (left) and 2559 (right).

lowing parameters were computed with the hydraulic model and used in this study: (i) inundation area, (ii) maximum water level, (iii) maximum flow velocity, (iv) maximum product of water level and flow velocity, (v) total duration of the flood event and (vi) duration of exceedance of certain threshold water levels.

\subsection{Socio-economic assessments}

With regard to a cost-benefit analysis the costs of the planned measures, including the direct costs of flooding agriculturally used polders were estimated. These costs were compared with possible reductions of damages. This economic analysis was done in a spatially distributed way in order to estimate the site-specific damage potential. Since pecuniary damage varies with flooding-specific parameters, the absolute or relative degree of damage was estimated using value and landuse type specific damage functions, which were based on flood height, velocity of the flow and flood duration. 
The damage functions were combined in a Geographic Information System (GIS) with landuse and hydraulic data in order to automate the calculation of geographically distributed economic risks, risks for affected persons, and vulnerable localities (e.g. schools, nursery homes, clinics, etc.) for all 186 flood events.

\subsection{Simulation results}

During the hydraulic simulations it became evident that the risk of increased damages connected with new polders can not be neglected. Especially for rare floods the hydraulic conditions worsened. In Thuringia several settlements were affected by floods if the volume-peak relationship is unfavourable and/or new polders zoned by levees would be built within natural retention areas.

In Fig. 6, the increase of damages for rare floods and an extended polder system can be seen. The flood damages differ significantly between floods of the same return period. It becomes evident that a large uncertainty of damages exists as each of the five floods represents a possible event with the same return period of the flood peak. Low-volume summer events, high volume spring floods, floods with multiple peaks, floods which are related to antecedent conditions of high soil moisture and floods with high spatial heterogeneity in precipitation were considered to characterise the variety of hydrological loads. It is shown in Fig. 6, that the performance of the flood retention systems differ significantly between flood events which have similar peaks. Obviously these differences are difficult to communicate to decision makers without the knowledge of the specific characteristics of the flood control system and its performance in relationship to the flood characteristics.

The differences between flood damages are also strongly related to different vulnerabilities of locations within the basin. This can be demonstrated with the example shown in Fig. 7. No flooding occurs during the 2320 event at a point of confluence within the river basin, in contrast to the 2559 event. However, even if the total flooded area is much larger in the 2559 event, almost no urban areas were affected. In contrast during the flood 2320 the runoff originated from the South-Eastern part (see Fig. 5), causing a flooding of the settlement Leubingen. These examples demonstrate the complexity of flood conditions which were addressed here.

As mentioned before, for every return period five events were selected on the basis of their volume, shape and spatial distribution. The results of the bivariate statistical analyses were used as indicators for the plausibility of the single events (Eq. 10). The most plausible of five possible events, together with the events' minimum and maximum plausibility, defined a fuzzy numbers which was assumed to be representative for this return period. An example of the resulting triangular fuzzy number is given in Fig. 8.

This representation of the varieties of flood consequences has two advantages: it reduces the complexity for the fol- lowing MCDM calculations, but more importantly, it can be visualized for decision makers. Large variations in shape and volume of the hydrographs of a specific return period result in a wide base of the fuzzy sets. For instance, one event with a univariate return period of the peak of 500 years has a very small volume. This peak-volume probability was estimated with a return period of 33 years. The resulting low damage has a very small plausibility considering this aspect. This reflects the fact that short flood events with very steep rising and falling limbs, caused by convective rainfall events are not representative for this large river basin. The maximum plausibility in this group of 500 years flood events has a bivariate probability of 593 years. This example explains how the plausibility was assessed: If the probability of the peak and the bivariate probability based on joint consideration of peak and volume are similar in their size, the event is a typical event with high plausibility. If the differences are large (in both directions), the plausibility of the event is smaller.

Figure 9 shows the range of damages for a largely extended flood control system (stage 6). The performance of the flood control system to reduce damages is high for return periods up to 100 years (triangles shift to the left). Also, the range of uncertainty increases for large events. This becomes visible in the increasing base of the triangles. The flood control measures in stage 6, although beneficial for more frequent events, may worsen the total amount of damages of extreme events (the shapes of the triangular fuzzy numbers shift and tend to the right).

This example shows how technical solutions for flood control are limited to the return period for which they were designed. It became evident that technical flood retention facilities such as polders situated in a natural inundation area may worsen the flood conditions. The same flood control measures which have positive effects on small floods could have negative impacts on rare events. The new levees constrict or hem the discharge in its course outside the river banks. The question is how this affects the total risks and, how this can be communicated to the decision maker. A crucial step in this communication is the combination of this information with the expected benefits of flood peak reductions and to balance both aspects. Here again the dependency of polder performance on the flood severity has to be considered. This was done with the fuzzy set representation of the results.

\subsection{Considering the varieties of multiple effects of flood control}

The expected value of flood induced losses can be estimated from the sum of the products of the values of damages times the probabilities of the causing floods. This concept is often used to characterise the flood risk. This can be done also with fuzzyfied risk values, but upper and lower limits and the values with the highest memberships have to be handled separately. The resulting relationship for the Unstrut catchment is displayed in Fig. 10. Figure 10 shows that the technical 

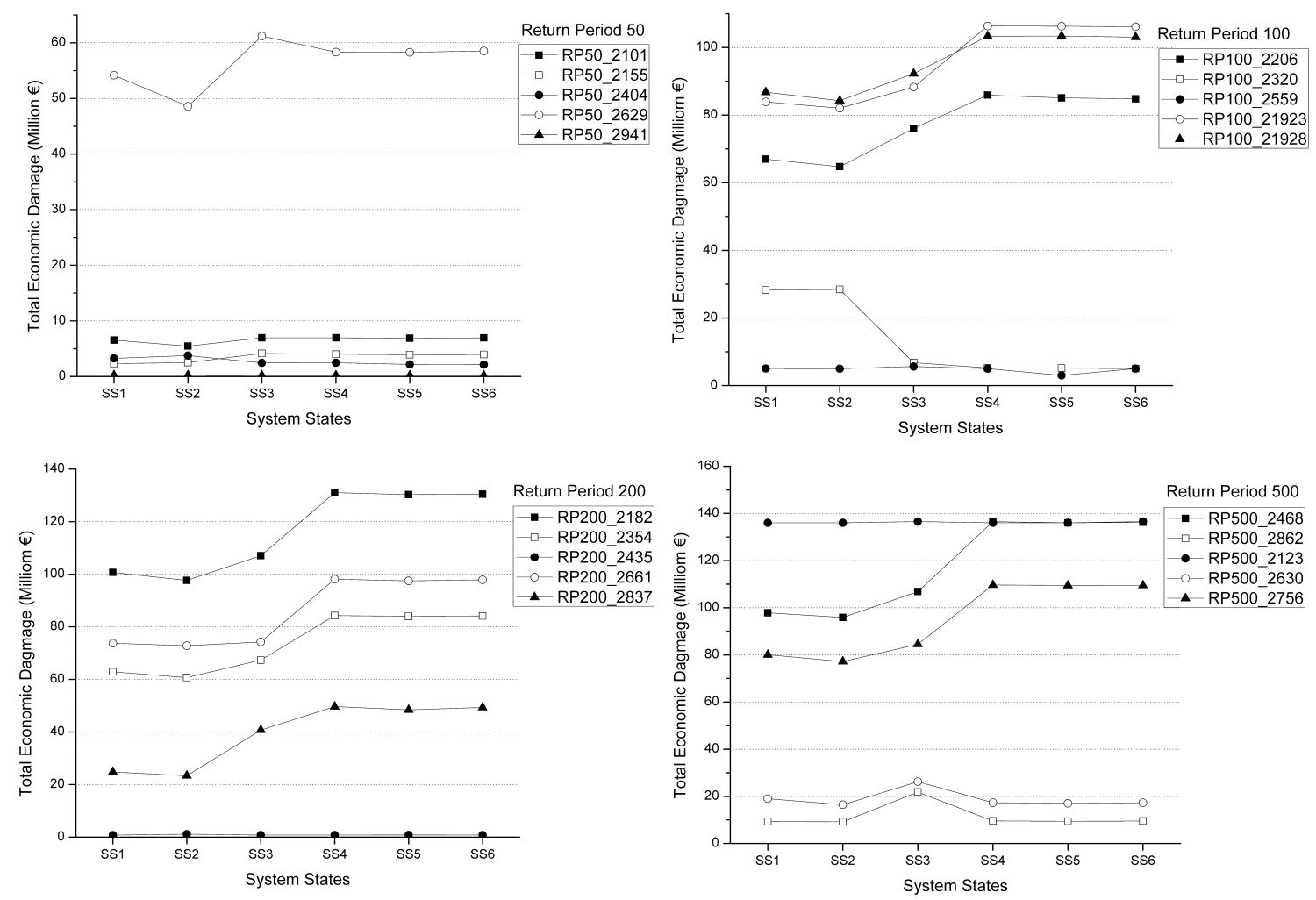

Fig. 6. Total economical damage caused by the 5 flood scenarios with different stages of extension, classified by the return periods of 50 (top left), 100 (top right), 200 (bottom left) and 500 (bottom right) years, based on.
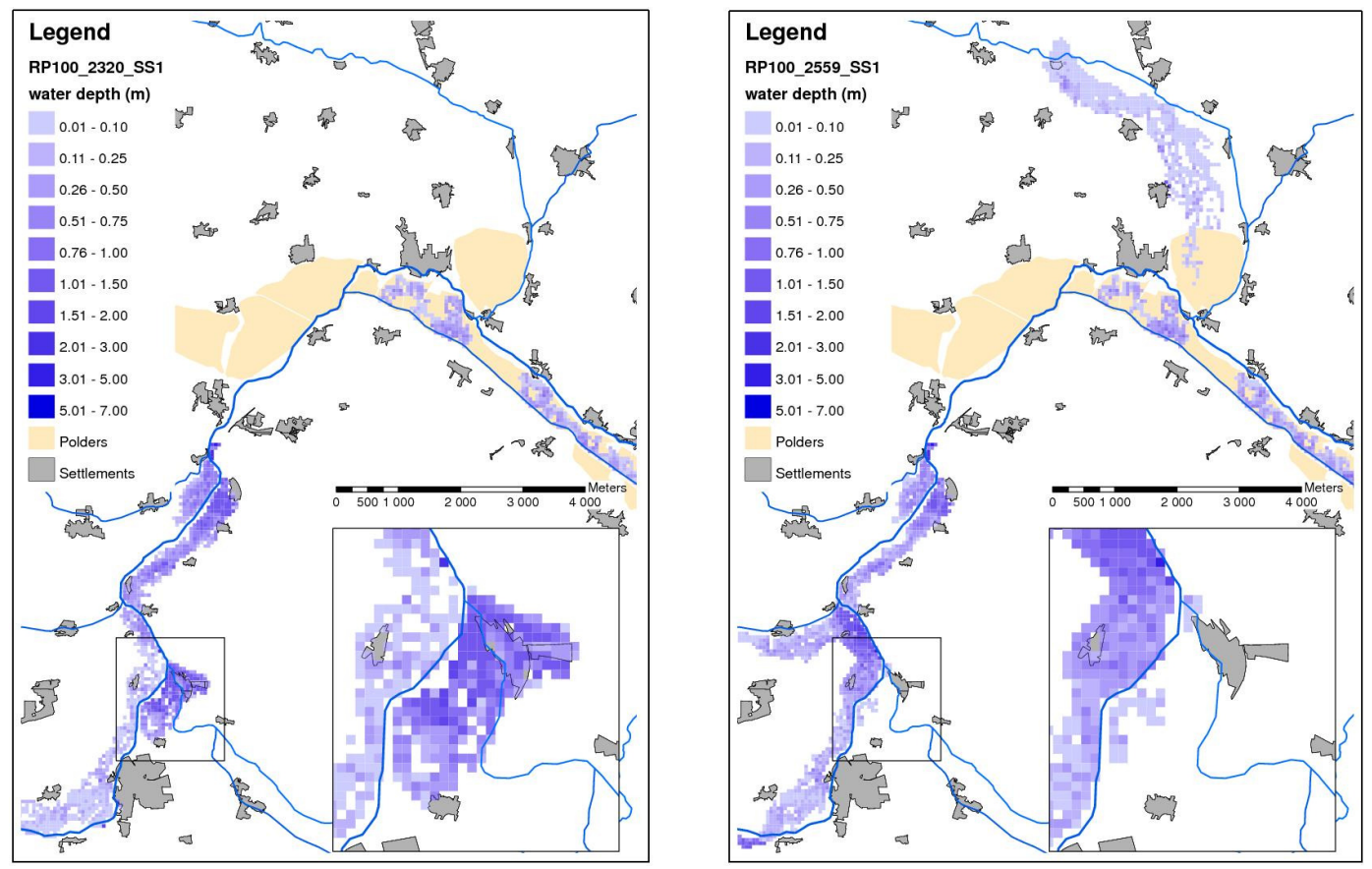

Fig. 7. Flooded area in the central part of the Unstrut basin for the 100 year events 2320 (left) and 2559 (right). 


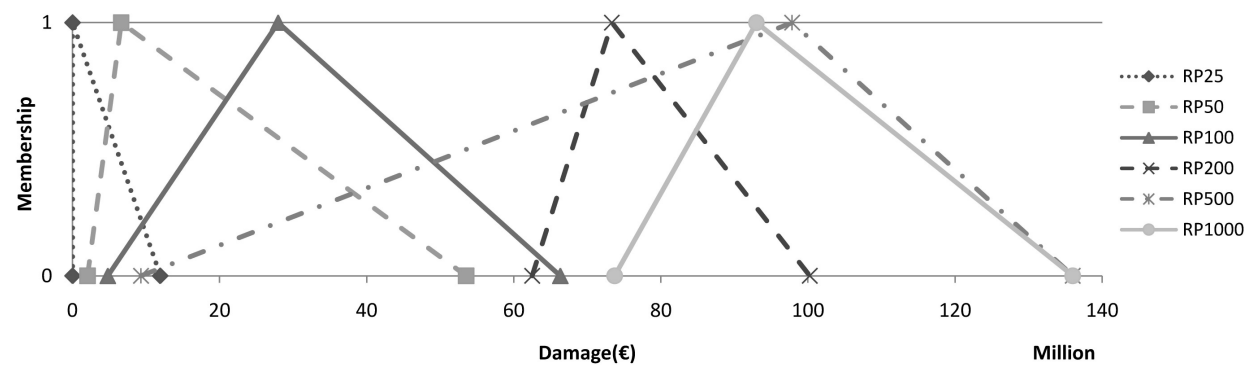

Fig. 8. Fuzzified damages for the reference system ("status quo") for the return periods RP 25, 50, 100, 200, 500 and 1000 years.

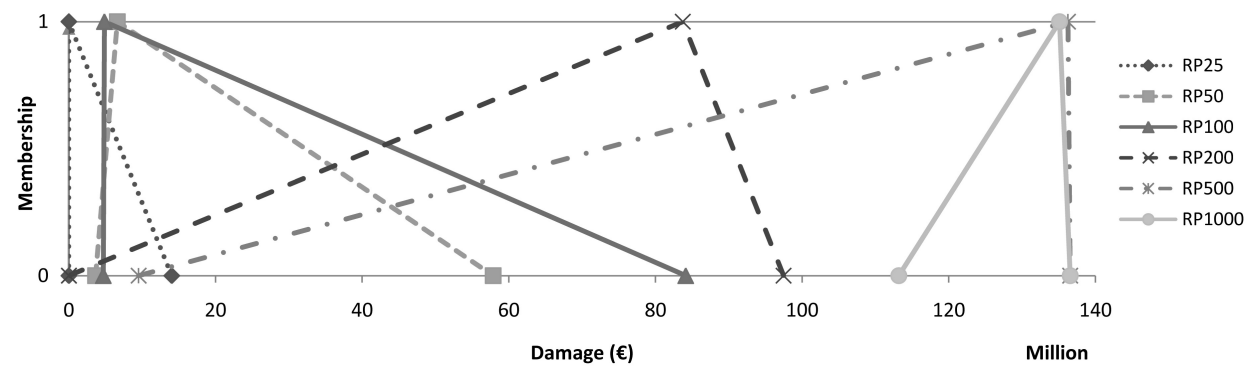

Fig. 9. Fuzzified damages for stage of extension 6, which encompasses the most elaborate flood protection measures, for the return periods $25,50,100,200,500$ and 1000 years.

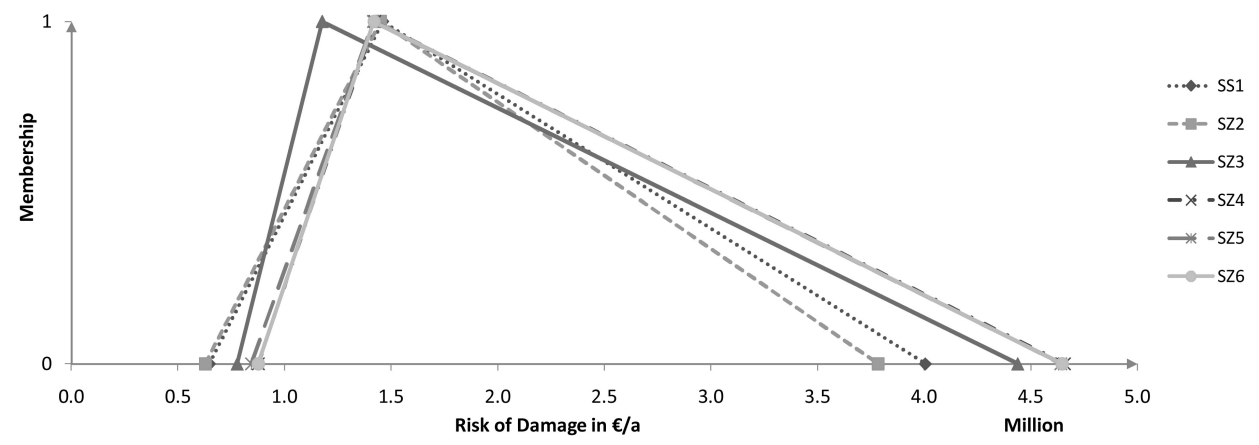

Fig. 10. Economical risks (in $€ / a$ ) for all stages of the system, integrated over the entire univariate probability interval.

solutions in stage 3 gives rise to the smallest risk of damages concerning the most possible events $(\mu=1)$. However, if we consider the other values of lower possibility, it seems that stage 2 could be a better solution. It comprises the lowest risk of damages, but more importantly, it has the lowest maximum risk of damages within the range of all analysed flood events. Nevertheless, the expected loss values are very similar.

The expected values integrate the risks over the range of probabilities. This can be interpreted as a weighting of the damages or risks for each return period according to their statistical frequencies. Therefore, damages that occur with a statistical frequency of once in 25 years are upscaled to a value which is 40 times more important than damages that occur once every 1000 years. This integration of the expected value does not considers that the risk aversion of society to catastrophical events is much higher than for events which cause a relatively small amount of damage even though they occur more frequently (Slovic and Weber, 2002; Merz and Thieken, 2007). Moreover, because of the higher weighting of frequent floods, the rare events with low effectiveness of flood control tend to be underestimated. This can be seen more clearly if economic damages are compared for different hydrological loads and stages of the flood retention system. With regard to the applied triangular fuzzy numbers the following equations were used to specify the degree to which a fuzzy number is larger than other fuzzy numbers (Chang, 1996):

$$
\begin{aligned}
& V\left[\left(M \geq M_{1}\right) \text { and }\left(M \geq M_{2}\right) \text { and. } \ldots \text { and }\left(M>M_{k}\right)\right] \\
& \quad=\min V\left(M \geq M_{i}\right)(i=1, \ldots k)
\end{aligned}
$$




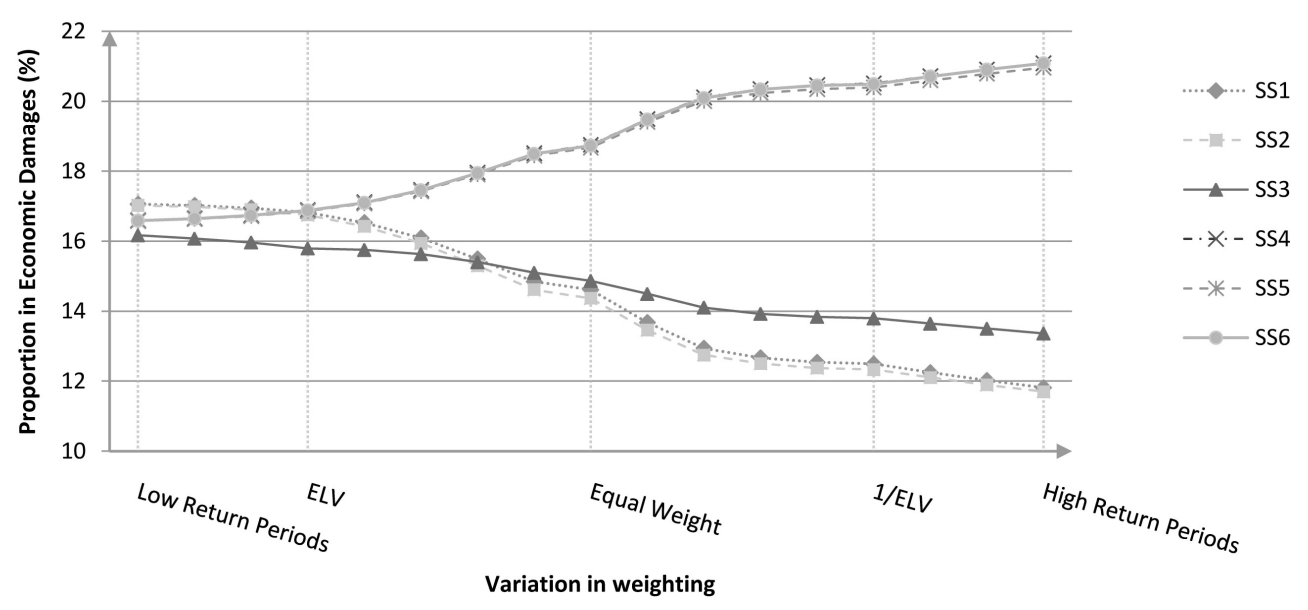

Fig. 11. Influences in the variation of weighing the return periods.

$V\left(M_{x}>M_{y}\right)$ has the value

$$
\begin{array}{cc}
1 & \text { if } m_{x} \geq m_{y} \\
0 & \text { if } l_{y} \geq u_{x} \\
\frac{l_{y}-u_{x}}{\left(m_{x}-u_{x}\right)-\left(m_{y}-l_{y}\right)} & \text { in all other cases }
\end{array}
$$

with $M_{x}$ and $M_{i}$ triangular fuzzy numbers with a lower bound $l$, an upper bound $u$ and a modal value $m . V$ is the degree to which $M_{x}$ is larger than all $M_{y}$.

As can be seen in Table 2, the relationships of economic damages differ between the individual stages of extension according to the return periods. Small or no differences can be detected among the different stages for the return periods 25 and 50 years. The construction of new polders (stages 3 to 6 ) has positive effects for a 100 year flood as the flood protection was designed for this occurrence. However, it becomes evident that the planned extensions of the flood defence systems, especially for the system stages 4,5 and 6 dramatically increase the damages caused by rare floods. The expected value would indicate system stage 3 as the best solution, because of the reduction in the importance of rare events, where system stages 4, 5 and 6 display the highest increase in damage.

The decision support system should give decision makers the opportunity to shift their focus of importance between more and less rare events. To allow this functionality, the different return periods can be handled as criteria, where the individual importance can be weighted. Figure 11 illustrates the importance of this weighting process: as the focus of the decision maker shifts from low return periods towards an equal weighing of return periods, the relative priorities concerning economic damages change. For the expected value (ELV) of all damages, system stage 3 results in the lowest value, but if every return period is weighted equally (without consideration of probabilities), system stage 1 and especially 2 are preferred.
Table 2. Defuzzified Proportion of economic damages for all stages of extension for all return periods RP $(25,50,100,200,500$ and 1000 years) and the defuzzified expected loss value (ELV).

\begin{tabular}{llllllll}
\hline & RP 25 & RP 50 & RP 100 & RP 200 & RP 500 & RP 1000 & ELV \\
\hline SS1 & 0.167 & 0.167 & 0.196 & 0.095 & 0.144 & 0.085 & 0.170 \\
SS2 & 0.167 & 0.167 & 0.196 & 0.082 & 0.142 & 0.085 & 0.169 \\
SS3 & 0.167 & 0.167 & 0.151 & 0.116 & 0.152 & 0.106 & 0.158 \\
SS4 & 0.167 & 0.167 & 0.153 & 0.237 & 0.188 & 0.242 & 0.168 \\
SS5 & 0.167 & 0.167 & 0.152 & 0.234 & 0.187 & 0.239 & 0.168 \\
SS6 & 0.167 & 0.167 & 0.152 & 0.236 & 0.187 & 0.243 & 0.168 \\
\hline
\end{tabular}

For all the other criteria, the same kind of analysis was carried out, visualising the risks per criterion and modifying its weight for each stage of extension. After this analysis the criteria were pooled.

Weighing different criteria according to their importance for society depends on subjective factors. Theses qualitative assessments can be expressed with fuzzy numbers (Chang, 1996; Srdjevic and Medeiros, 2008). Using a Fuzzy algorithm enables the decision support system to incorporate not only the hydrological uncertainties in the decision matrix, but also to consider uncertain qualitative assessments of decision makers about their preferences. Here the Fuzzy AHP methodology was applied. The following criteria were combined (Fig. 12):

- two risk components, economical risk and social risk (the social risk is represented by the numbers of affected inhabitants and of risk hot spots such as hospitals, kindergartens, schools etc.)

- reductions of risk downstream, which is characterized by a reduction of the water level during the flood peak (respective water level) at gauge Wangen

- costs of measures to improve flood control 


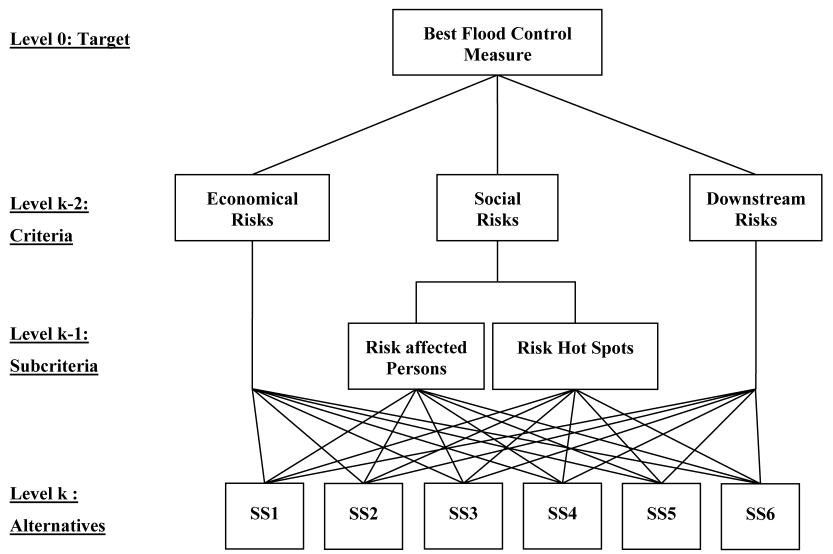

Fig. 12. Fuzzy AHP decision tree.

The spatial distributions of these criteria were considered by application of a GIS to differentiate the results among the two federal states. The costs were represented also with fuzzy numbers which were derived from an economic analysis of the construction, operation maintenance and replacement costs (Fig. 13).

In the decision support system, the decision maker has the option to vary the weights of return periods or to focus on individual damage criteria, e.g. on costs or benefits, in order to explore his decision space and to analyse the systems responses. Table 3 gives an overview of the outcome of three extreme decisions: total domination of economic criteria, total domination of social criteria and total focus on the reduction of the water level differentiated among floods with low and high return periods. For clarity, the fuzzy priorities are translated into rankings of the different stages of extension of the flood control system (see Table 3). These results can be interpreted as follows.

If we focus on economic damages, the existing system (stage SS1) delivers suboptimal results for flood events which happen more often. It is in need for improvement. Technically low-level interventions such as replacing flood locks with overflow dikes and new inflow gates (stage SS2) reduce the predicted economic damages. Increasing the number of polders and thus the number of dikes in the floodplain (stage SS3) reduces the predicted economic damages for events with low return periods. For high return periods, the current system seems to be the best alternative as no additional flood risk is created. It is improved slightly by the measures of stage 2 (stage SS2). These results were verified with the flood of 2002. Here the existing retention system (stage SS1) failed. The polders were only flooded to a small percentage of their capacity because of malfunctioning inlet systems, causing a severe flooding and consequently high damages downstream. The inherent danger of altering the course of flooding through the construction of new polders becomes evident in stage SS3: new areas were inundated

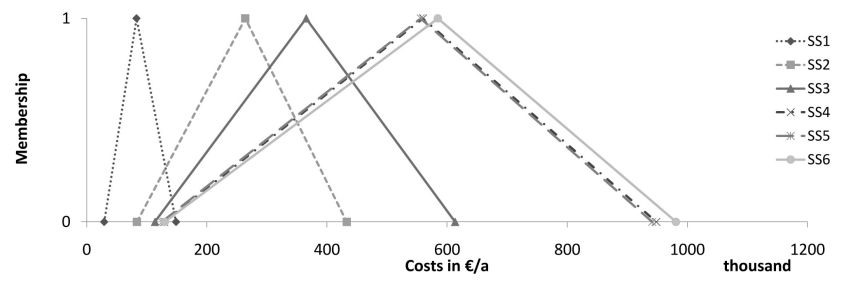

Fig. 13. Combined costs (construction and maintenance costs, harvest losses due to flooding of the polder system) for the different stages of extension.

Table 3. Ranking for the stages of extension according to a different prioritisation of the criteria for both low and high return periods.

\begin{tabular}{llll}
\hline Criteria & Stage & $\begin{array}{l}\text { Low } \\
\text { Return } \\
\text { Periods }\end{array}$ & $\begin{array}{l}\text { High } \\
\text { Return } \\
\text { Periods }\end{array}$ \\
\hline \multirow{5}{*}{ Economical damages } & SS1 & 3 & 2 \\
& SS2 & 2 & 1 \\
& SS4 & 1 & 3 \\
& SS5 & 4 & 6 \\
& SS6 & 5 & 4 \\
\hline \multirow{5}{*}{ Social Effects } & SS1 & 6 & 2 \\
& SS2 & 5 & 3 \\
& SS3 & 1 & 1 \\
& SS4 & 4 & 6 \\
& SS5 & 2 & 4 \\
& SS6 & 3 & 5 \\
\hline \multirow{5}{*}{ Downstream Water } & SS1 & 6 & 1 \\
& SS2 & 5 & 6 \\
& SS3 & 3 & 2 \\
& SS4 & 2 & 3 \\
& SS5 & 4 & 4 \\
& SS6 & 1 & 5 \\
\hline
\end{tabular}

during a flood. Moreover, by reducing the cross-sectional area of floods, backflow may occur, causing a local increase in flood level. In stage 4, the total length of polder dikes is increased (an increase of more than $8 \mathrm{~km}$ compared to stage 3 ), causing a dramatic rise in economic damages, as well as in endangered persons. It became obvious that the technical solution of uncontrolled polders has reached its limit in stage 3. These results demonstrate the negative effects of system stage 4 most clearly. The adverse effects of backflow can be reduced if overflow dikes are replaced by controlled weirs with a reduced bottom sill (in order to retain the same flow capacity) (stage 5). However if the breadth of the controlled weirs is doubled (stage SS6), the polders are being filled too fast (in combination with the reduced bottom sill), which causes the effect of backflow to re-emerge. Thus stage 6 would be excellent with regard to small floods, but it would fail more often during rare large floods. 
Focussing on the affected inhabitants the differences between measures are similar but the spatial distribution of damages changes according to the structure of land use. Similar effects were estimated when the number of affected persons is selected instead of economic damages. The flooded area determines both criteria. However, a slight difference can be seen in system stage 3, which is the best for both low and high return periods with regard to social damages. This is explained by the difference between both criteria: flooded industrial sites or business areas have a large impact on economic damages, whilst a flooding of residential areas has a larger impact on the number of affected inhabitants. It can be shown that the increase in the performance (displayed as a reduction in risk) of stage 3 results from a reduction of flooded industrial and business sides which is considered in the economic criteria. The differences in landuse of the flooded areas is also the cause of discrepancies between stages for low return periods. It became evident that floods with low frequencies have more impact on residential areas than floods which occur more often.

\section{Summary and conclusions}

The shift from a safety oriented planning towards risk awareness demands consideration of the variety of hydrological processes. Instead of focussing on one specific event which is used as a design flood it becomes necessary to pay attention on the large amount of possible realisations of flood events within one river basin. However, it is essential to specify the possibility of these events. It is not sufficient to concentrate on worst cases or extremely maximized events only. An estimation of probabilities of such events is essential. Unfortunately the data bases are in general insufficient to specify the variety of possible realizations of flood conditions, especially in large river basin. Thus simulation tools have to be applied. The results of long term simulations can be interpreted as a characterization of natural variabilities. However, the large number of assumptions which are included in complex simulations reduce the statistical meaning of the results. To consider the differences between statistical descriptions based on measured data and statistics which were derived from simulated data, imprecise probabilities were introduced, which were specified with fuzzy numbers to provide measures of possibilities. Triangular fuzzy numbers were used to specify the additional characteristic "possibility" as a degree of membership of a flood scenario to the set of events with the same return period of the flood peak. A fuzzy approach was also applied to specify the uncertainties of weightings, which have to be defined by decision makers according to their preferences. In the developed planning system the following extensions with regard to a risk oriented planning were realized.

- a large variety of flood events, differing in size, volume, shape of the flood waves and spatial distributions of runoff was considered,
- the single flood scenarios were characterized by multiple probabilities, which were summarized by two criteria, the return periods of the flood peak (which is the common approach) and a new measure of possibility, which was derived from multivariate statistical analyses,

- the measures of possibility were interpreted as imprecise probabilities and described with triangular fuzzy numbers,

- the fuzzy numbers represent the variety of possible outcomes of flood events, which can be compared to demonstrate the effects of single measures,

- the inundated areas, damage functions and landuse information were combined to specify the resulting damages,

- a fuzzy approach was used also in the MCDM-tool (Fuzzy AHP), which was applied to integrate criteria.

In this study it was shown that a detailed analysis of options and limitations of complex flood control measures can provide a firm basis for flood management planning. The specification of remaining risks should not only consider that planned flood control structures may fail, but also the risk of additional negative consequences, caused by these measures in case of overloading their capacities under unfavourable hydrological conditions.

Acknowledgements. Funding for this work, provided by the German Ministry for Education and Research (BMBF grant number 02WH0588) and data from the Ministry of Agriculture, Nature Conservation and the Environment of Thuringia (TMLNU) and the Ministry of Agriculture and Environment of Saxony-Anhalt (MLU LSA) are gratefully acknowledged. The authors are also indebted to $\mathrm{K}$. Beven and one anonymous referee for their suggestions.

Edited by: M. Disse

Reviewed by: K. Beven and another anonymous referee

\section{References}

Berlekamp, J., Zerger, A., Lauterbach, S., Graf, N., Matthies, M., and Argent, R. M.: A decision support system for integrated river basin management of the German Elbe, Australia, Modelling and Simulation Society of Australia and New Zealand Inc., 2005.

Beven, K. J.: On undermining the science?, Hydrol. Process., 20, 3141-3146, 2006.

Blazkova, S. and Beven, K.: Flood frequency estimation by continous simulation for a catchment treated as ungauged (with uncertainty), Water Resour. Res., 38, 1139, doi:10.1029/2001WR000500, 2002.

Boender, C. G. E., De Graan, J. G., and Lootsma, F. A.: Multicriteria decision analysis with fuzzy pairwise comparison, Fuzzy Set. Syst., 29, 133-143, 1989. 
Chang, D.-Y.: Applications of the extent analysis method on fuzzy AHP, Eur. J. Oper. Res., 95, 649-655, 1996.

Cameron, D. S., Beven, K. J., Tawn, J., Blazkova, S., and Naden, P.: Flood frequency estimation by continuous simulation for a gauged upland catchment (with uncertainty), J. Hydrol., 219, 169-187, 1999.

Deng, H.: Multicriteria analysis with fuzzy pairwise comparison, the treatment of uncertainity in artificial intelligence, Int. J. Approx. Reason., 21, 215-232, 1999.

Favre, A. C., El Adlouni, S., Perreault, L., Thiemonge, N., and Bobee, B.: Multivariate hydrological frequency analysis using copulas, Water Resour. Res., 40, 1-12, W01101, 2004.

Fell, R. and Hartford, D.: Landslide Risk Management, in: Landslide Risk Assessment, edited by: Cruden, D. and Fell, R., Balkema, 51-110, 1997.

Genest, C. and Favre, A. C.: Everything you always wanted to know about copula modeling but were afraid to ask, J. Hydrol. Eng., 12(4), 347-368, 2007.

Grimaldi, S. and Serinaldi, F.: Asymmetric copula in multivariate flood frequency analysis, Adv. Water Resour., 29(8), 1155-1167, 2006.

Haimes, Y. Y.: Risk analysis of fracture and failure, Mater. Res. Innov., 2, 16-21, 1998.

Hundecha, Y., Pahlow, M., Klein, B., and Schumann, A.: Modelling of daily rainfall for flood risk assessment using a mixed distribution, Water Resour. Res., submitted, 2009.

Joe, H.: Multivariate Models and Dependence Concepts, Chapman and Hall, New York, 1997.

Kachroo, R. K.: Storage required to augment low flows - a regional study, Hydrolog. Sci. J., 37, 247-261, 1992.

Kamrath, P., Disse, M., Hammer, M. and Köngeter, J.: Assessment of discharge through a dike breach and simulation of flood wave propagation, Nat. Hazards, 38, 63-78, 2006.

Klein, B., Pahlow, M., Hundecha, Y., and Schumann, A.: Probability analysis of hydrological loads for the design of flood control systems using copulas, J. Hydrol. Eng., submitted, 2009.

Klir, G. J. and Smith, R. M.: On measuring uncertainty and uncertainty-based information: Recent developments, Ann. Math. Artif. Intel., 32, 5-33, 2001.

Koutsoyiannis, D. and Onof, C.: Rainfall disaggregation using adjusting procedures on a Poisson cluster model, J. Hydrol., 246, 109-122, 2001.

Koutsoyiannis, D., Onof, C., and Weather, H.: Multivariate rainfall disaggregation at a fine time scale, Water Resour. Res., 39(7), 1173, doi:10.1029/2002WR001600, 2003.

Krupnick, A., Morgenstern, R., Batz, M., Nelson, P., Burtraw, D., Shih, J.-S., and McWilliams, M.: Not a Sure Thing: Making Regulatory Choices Under Uncertainty, Resources for the Future, Washington, DC, 233 pp., 2006.

Lamb, R.: Confidence intervals for a spatially generalized, continuous simulation flood frequency model for Great Britain, Water Resour. Res., 40, W07501, doi:10.1029/2003WR002428, 2004.

Lindström, G., Johansson, B., Persson, M., Gardelin, M., and Bergström, S.: Development and test of the distributed HBV-96 model, J. Hydrol., 201, 272-288, 1997.
McMillan, H. K. and Brasington, J.: End-to-end flood risk assessment: A coupled model cascade with uncertainty estimation, Water Resour. Res., 44, W03419, doi:10.1029/2007WR005995, 2008.

Merz, B.: Hochwasserrisiken, Grenzen und Möglichkeiten der Risikoabschätzung, E. Schweizerbart'sche Verlagsbuchhandlung (Nägele u. Obermiller) Stuttgart, 2006.

Merz, B. and Thieken, A.: Die Bedeutung von extremen Ereignissen in der Risikoquantifizierung, ÖWAV-Seminar 2007, TU Wien, 117-131, 2007.

Morss, R. E.: Flood Risk, Uncertainty, and Scientific Information for Decision Making - Lessons from an Interdisciplinary Project, American Meteorological Society, B. Am. Meteorol. Soc., 86(11), 1593-1602, doi:10.1175/BAMS-86-11-1593, 2005.

Nelsen, R. B.: An Introduction to Copulas, Springer, New York, 1999.

Plate, E. J. and Meon, G.: Stochastic aspects of dam safety analysis, Proc. Of JSCE, No. 393/II-9 (Hydraulic and Sanity Eng.), 1-8, 1988.

Plate, E. J.: Flood risk and flood management, J. Hydrol., 267, 2$11,2002$.

Saaty, T. L.: The analytic hierarchy process - planning, priority setting, resource allocation, 1980.

Salvadori, G. and De Michele, C.: Frequency analysis via copulas: Theoretical aspects and applications to hydrological events, Water Resour. Res., 40(12), W12511, doi:10,1029/2004WR003133, 2004.

Salvadori, G., De Michele, C., Kottegoda, N. T., and Rosso, R.: Extremes in Nature: An Approach Using Copulas, Springer, Dordrecht, 2007.

Sklar, A.: Fonctions de reparttion à $\mathrm{n}$ dimensions et leura Marges, Publ. Inst. Stat. Univ. Paris, 8, 220-231, 1959.

Slovic, P. and Weber, E. U.: Perception of Risk Posed by Extreme Events, Risk Management strategies in an Uncertain World, Columbia University and Wissenschaftskolleg zu Berlin, New York, 1-21, 2002.

Srdjevic, B. and Medeiros, Y.: Fuzzy AHP Assessment of Water Management Plans, Water Resour. Manag., 22, 877-894, 2008.

Thieken, A. H., Kreibich, H.,Müller, M., and Merz, B.: Coping with floods: preparedness, response and recovery of flood-affected residents in Germany in 2002, Hydrolog. Sci. J., 52, 1016-1037, 2007.

Van Laarhoven, P. J. M. and Pedrycz, W.: A fuzzy extension of Saaty's priority theory, Fuzzy Set. Syst., 11, 229-241, 1983.

Walley, P.: Statistical Reasoning with Imprecise Probabilities, Chapman and Hall, London, 1991.

Zadeh, L. A.: Fuzzy Sets, Information and Control, 8, 338-353, 1965.

Zadeh, L. A.: Probability measures of Fuzzy Events, J. Math. Anal. Appl., 23, No. 2, August 1968.

Zadeh, L. A.: Toward a generalised theory of uncertainty (GTU) an outline, Inform. Sciences, 172, 1-40, 2005. 